Recebido: $28 / 10 / 2018$

Aprovado: 28/01/2019

\title{
Disputa entre Memórias Enquadradas e Subterrâneas nas manifestações ocorridas na Polícia Militar do Maranhão no ano de 2011: observações preliminares
}

Paulo Henrique Matos de Jesus ${ }^{1}$

Resumo: $O$ presente artigo pretende apresentar um panorama historiográfico ancorado cronologicamente no tempo presente. Primeiramente, apresentam-se as perspectivas analíticas de Reinhart Koselleck e François Hartog sobre o tempo, regimes de historicidade e tempo presente. Em seguida, os estudos sobre o tempo presente fundamentados no campo teórico da Nova História Política. Conseguinte, faz-se uma análise das memórias enquanto campo de gestão do passado e o uso dos recursos metodológicos da História oral como ferramentas adequadas para tal análise. Por fim, oferece-se uma análise/observação da Polícia Militar do Maranhão (PM-MA) como campo de disputas de memórias a partir das manifestações realizadas em 2011 por parte de seus quadros, podendo ser

\footnotetext{
${ }^{1}$ Mestrando no Programa de Pós-graduação em História da Universidade Federal do Maranhão (PPGHISUFMA). Pesquisador do Núcleo de Estudos de Estado, Segurança Pública e Sociedade da Universidade Federal do Maranhão (NEESS-UFMA). Integrante do Núcleo de Estudos de Poderes e Instituições, Mundos do Trabalho e Ideias Políticas (POLIMT/PPGHIS-UFMA). Contato: pauloesquizo@gmail.com .
} 
compreendidas como elemento de uma complexa teia de problemas que cercam a segurança pública no Brasil.

Palavras-chaves: Memórias; Tempo Presente; Polícia Militar.

\begin{abstract}
The present article intends to present a historiographic panorama anchored chronologically in the present time. First, we present the analytical perspectives of Reinhart Koselleck and François Hartog on time, regimes of historicity and present time. Next, the present time studies are based on the theoretical field of New Political History. Consequently, an analysis of the memories as a field of management of the past and the use of the methodological resources of Oral History as appropriate tools for such analysis is made. Finally, an analysis / observation of the Military Police of Maranhão (PM-MA) is offered as a field of disputes of memories from the manifestations carried out in 2011 by its cadres, and can be understood as an element of a complex web of problems which surrounds public safety in Brazil.
\end{abstract}

Keywords: Memories; Present Time; Military Police.

\title{
Tempo presente: possibilidades teóricas
}

É cada vez maior o número de historiadores, tanto no plano internacional quanto nacional, que vêm aderindo às análises relacionadas à história do tempo presente. Este fato pertence a um fenômeno mais amplo de avanço das perspectivas historiográficas que trouxe no seu bojo uma espécie de revigoramento da história política, o aumento do uso de fontes, maior interação com as ciências sociais, busca por novos conteúdos investigativos, observação de agentes históricos coletivos e individuais e maior diálogo entre história e memória.

Toda essa dinâmica é também caracterizada por determinante análise epistemológica que propicia profunda reflexão sobre as particularidades teóricometodológicas dessa nova maneira de fazer história. A escolha do tempo presente como temporalidade fundamental para problematizações e reflexões é recente e, ao mesmo tempo, bastante fértil em sua viabilidade de elaboração de maneiras diferenciadas de saber histórico que presumem constantes reavaliações do próprio campo da história, da elaboração de novas perspectivas, noções de territorialidade, elaboração de inúmeras possibilidades dialógicas com as mais diversas áreas do conhecimento e pela busca por novos conteúdos investigativos. Além do que, requer constante e profundo esforço

\section{Filistorórias}


analítico que tome em consideração perspectivas teóricas e corolários de pesquisa, constituídos em uma escrita própria da história que recorre ao passado recente numa dinâmica que interage com as temporalidades.

Nesse sentido, o presente artigo pretende promover a apresentação de um panorama historiográfico ancorado cronologicamente no tempo presente. Para tanto, opta-se por sua divisão em três partes distintas, mas que se complementam. Na primeira parte apresentam-se as perspectivas analíticas de Reinhart Koselleck e François Hartog sobre o tempo, regimes de historicidade e tempo presente. Em seguida, compreendendo a possibilidade de promoverem-se estudos sobre o tempo presente fundamentados no campo teórico da Nova História Política, será feito um balanço deste campo teórico desde o seu relativo abandono, em virtude da ascensão da $1^{\text {a }}$ geração da Escola dos Annales, no final dos anos 20, até a retomada do seu prestigio e sua reorganização no final da década de 1970, quando assumiu a condição de uma Nova História Política. Ao mesmo tempo, serão apresentadas as possibilidades de análise das memórias enquanto campo de gestão do passado e o uso dos recursos metodológicos da História oral como ferramentas adequadas para tal análise. Por fim, será apresentada uma operação analítica que propõe a observação da Polícia Militar do Maranhão (PM-MA) como campo de disputas de memórias que possibilitaram a ocorrência das manifestações realizadas por parte de seus quadros no ano de 2011 e que podem ser compreendidas como parte de uma complexa teia de problemas que cercam a segurança pública no Brasil.

\section{Noções de temporalidade a partir da perspectiva de Reinhart Koselleck e François}

\section{Hartog}

Partindo do pressuposto que uma das principais diferenças entre as análises históricas convencionais e a história do tempo presente é a proximidade dos historiadores em relação aos episódios por ele analisados, isto significa que o historiador é praticamente contemporâneo ao seu objeto de estudo. Por isso, pode-se afirmar que a constituição da história do tempo presente está intrinsicamente ligada aos aspectos temporais.

Para promover tal problematização faz-se necessário recorrer ao diálogo entre os historiadores Reinhart Koselleck e François Hartog, cujas elucubrações foram essenciais para a elaboração de importantes postulados sobre o tempo.

A primeira perspectiva teórica que será utilizada é a do historiador alemão

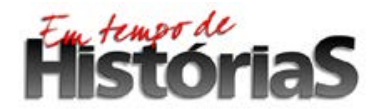

(PPGHIS/UnB) Nº. 33, Brasília, Ago - Dez 2018 ISSN 2316-1191 
Koselleck. É importante que se faça uma pequena reflexão sobre seu conceito de tempo histórico que se constitui tanto de forma relacional, quanto a partir da diferença entre passado e futuro. Tendo por fundamento uma nomenclatura calcada na antropologia, Koselleck (2006: 16), assinala que “[...] entre experiência e expectativa constitui-se algo como um “tempo histórico””. Ou seja, na maneira como cada época lidou com seu passado, constituindo seu campo de experiência e com seu futuro, propondo um horizonte de expectativas formou-se uma conexão com o tempo que nos permite identificá-lo como tempo histórico. Para o referido autor os tempos modernos se apresentam pelo gradativo distanciamento entre experiência e expectativa: “só se pode conceber a modernidade como um tempo novo a partir do momento em que as expectativas passam a distanciarse cada vez mais das experiências feitas até então” (KOSELLECK, 2006: 314). Ora, dessa maneira o tempo histórico é, também, historicizado na medida em que as estratégias relacionais entre passado e futuro podem ser modificadas em consonância com cada geração. Dessa forma, considera-se que: “à medida que o homem experimentava o tempo como um tempo sempre inédito, como um novo 'tempo moderno', o futuro lhe parecia cada vez mais desafiador” (KOSELLECK, 2006: 16).

François Hartog, por sua vez, atesta que há períodos em que os homens se indagam sobre sua interação com o tempo e apresenta o conceito de regime de historicidade para analisar tal interação. Sobre uma viável conceituação afirma que:

O uso que proponho do regime de historicidade pode ser tanto amplo, como restrito: macro ou micro-histórico. Ele pode ser um artefato para esclarecer a biografia de um personagem histórico (tal como Napoleão, que se encontrou entre o regime moderno, trazido pela Revolução, e o regime antigo, simbolizado pela escolha do Império e pelo casamento com Maria-Luisa de Áustria), ou a de um homem comum; com ele pode-se atravessar uma grande obra (literária ou outra), tal como as Mémoires d'outre-tombe de Chateaubriand (onde ele se apresenta como o 'nadador que mergulhou entre as duas margens do rio do tempo'); pode-se questionar a arquitetura de uma cidade, ontem e hoje, ou então comparar as grandes escansões da relação com o tempo de diferentes sociedades, próximas ou distantes. E, a cada vez, por meio da atenção muito particular dada aos momentos de crise do tempo e às suas expressões, visa-se a produzir mais inteligibilidade (HARTOG, 2014: 13).

Desta forma a perspectiva de Hartog se confronta com a concepção de uma história linear fundamentada em Fukuyama que parte do princípio de que a história teria chegado ao fim em virtude de todos os ciclos revolucionários já terem sido vivenciados e

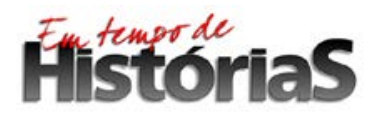

(PPGHIS/UnB) No. 33, Brasília, Ago - Dez 2018 ISSN 2316-1191 
os valores democráticos haviam por fim se estabilizado e concretizado no mundo ocidental.

Para Hartog, torna-se impossível produzir a história a partir da perspectiva do futuro (visto que não há mais um rumo norteador) e que passado e futuro não existem mais. Quando ocorre a passagem de um regime de historicidade para outro, ou seja, quando um regime é contestado e ocorre uma quebra ou lapso epistemológico, criando uma fase transitória, uma espécie de terceiro regime que se interpõe entre o regime de historicidade que se encerra e o que se inicia. Esse período transitório tem como principal característica o presentismo.

Segundo Hartog (2003: 27),

\begin{abstract}
Como a presença do presente, que crescia inexorável, inundasse tudo, um papel determinante foi certamente desempenhado pelas solicitações do mercado, o funcionamento de uma sociedade de consumo, as mudanças científicas e técnicas, os ritmos das mídias, que cada vez mais rapidamente tornam tudo (bens, acontecimentos, pessoas) obsoleto.

Assim fomos do futurismo para o presentismo e ficamos habitando um presente hipertrofiado que tem a pretensão de ser seu próprio horizonte: sem passado sem futuro, ou a gerar seu próprio passado e seu próprio futuro. Múltiplos sinais disto: nossas atitudes para com a morte, assim justamente estudadas por Philippe. Ariès, a extrema valorização da Juventude, todas as técnicas que tendem a suprimir o tempo (o tempo do computador e o 'tempo real').
\end{abstract}

Sobre a definição de tempo presente opta-se por buscar fundamentação teórica na perspectiva de Koselleck, para quem o conceito tempo presente é dinâmico e vem sendo elaborado e reelaborado ao longo da história, posiciona-se de maneira inversa aos conceitos chamados por ele de generalizadores e naturalizantes. Para ele o conceito de tempo presente é complexo, de difícil absorção e que assume constantemente diferentes noções de ser “presente”. A grande indagação feita por ele é: “Por qué ahora esta historia del tempo presente y no aquélla o ya no aquélla?” (KOSELLECK, 2001: 115). Dessa maneira, afirma-se que o primeiro grande obstáculo se apresenta tanto nas indagações anteriores quanto nas posteriores: tem fundamento a pergunta sobre em que lugar se origina o tempo presente e até onde ele vai? Até o infinito? Um presente que se estende sem parar em direção ao futuro? Um presente que se alarga em dimensão sincrônica? É somente a ponta de lança que nos leva a uma dimensão diacrônica? Elementos essenciais que se colocam diante dos historiadores, gerando uma infinidade de choques e

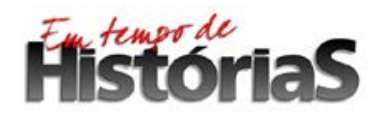


repercussões.

Em sua complexa análise do presente Koselleck propõe reflexões supostamente opostas. Por um ponto de vista o presente é aquela noção fadada ao desaparecimento, visto que, sendo um ponto de junção entre passado e futuro, representa simultaneamente um futuro que ainda não é e um passado que já foi se constituindo em um eixo temporal imaginário. Desta maneira "La actualidad se convierte em uma nada pensada que siempre nos indica nossa pertinência tanto al passado como al futuro. Se convierte em aquel momento que continuamente se escapa” (KOSELLECK, 2001: 116).

Entretanto, a reflexão sobre o presente, visto na perspectiva de Koselleck, pode ser feita de maneira contrária:

Así como el presente desaparece entre el passado y el futuro, la idea también se puede inverter hasta el extremo: todo tempo es presente em sentido próprio. Pues el futuro todavia no es y el pasado ya no es. Sólo hay futuro como futuro presente y pasado como pasado presente (KOSELLECK, 2001: 117).

Koselleck segue afirmando que: "Las três dimensiones del tempo se anudam em el presente de la existência humana”. Com base neste raciocínio o tempo presente concentra em si tanto passado quanto futuro, possibilitando a seguinte afirmação: “El tempo sólo está presente em uma continua retirada:el futuro en la expectatio futurorum y el pasado em la memoria praeteritorum” (KOSELLECK, 2001: 117). Desse modo, Koselleck concebe a possibilidade de muitos historiadores realizarem operações metodológicas que vislumbrem as três dimensões temporais (passado, presente e futuro) em algo único que, simultaneamente, desaparece, se funde e permite transmitir a perspectiva de que toda história se faz no tempo presente e cabe a esse mesmo historiador fazer indagações ao passado a partir de suas inquietações no presente.

\section{Nova História Política, Memórias como campo de gestão do passado, História Oral e Imprensa}

A história do tempo presente enquanto possibilidade historiográfica permite uma grande diversidade de temas e abordagens na montagem de problematizações sobre os conteúdos pesquisados. Entre estas possibilidades destacam-se os estudos pautados na Nova História Política ou História Política Renovada, em especial, em íntima relação com

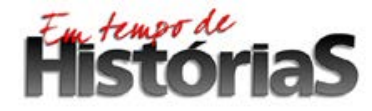

(PPGHIS/UnB) No. 33, Brasília, Ago - Dez 2018 ISSN 2316-1191 
as memórias em suas mais diversas manifestações.

No que diz respeito ao caminho percorrido pela História Política nota-se que até o final do século XIX ela possuía enorme destaque. “Todavia, a partir da fundação da revista Annales, em 1929 e a criação da VI Seção da École Pratique des Hautes Études, presidida por Lucien Febvre, em 1948” (FERREIRA, 1992: 265). A História Política passa a ser questionada por diversos historiadores que sustentavam a tese de que tal ramo era repleto de equívocos e falhas interpretativas, tais como: a exaltação da minoria, construção de uma história vista por cima, superficial e que não se preocupava em buscar as razões e análises mais densas dos episódios históricos. Além disso, essa nova geração de historiadores destaca a importância maior do econômico e social em detrimento do político, numa clara intenção hierarquizante da narrativa historiográfica. Visto que,

\footnotetext{
Desejosa de ir ao fundo das coisas, de apreender o mais profundo da realidade, essa nova história sustentava que as estruturas duráveis são mais reais e determinantes que os acidentes de conjuntura. Seus pressupostos eram que os fenômenos inscritos em uma longa duração são mais significativos do que os movimentos de fraca amplitude, e que os comportamentos coletivos têm mais importância sobre o curso da história do que as iniciativas individuais. As realidades do trabalho e da produção, e não mais regimes políticos, deveriam ser objeto da atenção dos historiadores. Enfim, o fundamental era o estudo das estruturas: 0 importante não é aquilo que é manifesto, aquilo que se vê, mas o que está por trás do manifesto. Tudo o que é manifesto é ao mesmo tempo mais superficial (FERREIRA, 1992: 265).
}

A discriminação em relação à História Política se agudiza na década de 1960 em virtude da ampliação das ideias marxistas na França e de sua maior interação com os Annales. Nesse momento crescem as críticas ao Estado que passa a ser tratado como ferramenta de manutenção do poder e interesses das classes dominantes (Cf. FERREIRA, 1992: 266). O Estado passou a ser o grande culpado por todos os problemas econômicos e sociais, tornando a história política, na maneira como era feita, uma espécie de “cúmplice” de tal situação.

Entretanto, aos poucos esse cenário foi passando por transformações e alguns historiadores da terceira geração dos Annales voltaram suas atenções para os estudos da História Política. Entre eles estavam René Rémond, Jacques Julliard, Jacques Le Goff, Roger Chartier, Antoine Prost, Serge Berstein, Jean-Pierre Rioux, além de outros.

O regresso do foco de vários historiadores para História Política pode ser

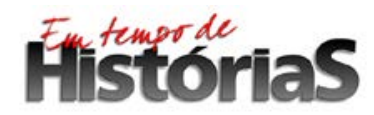


compreendido a partir de duas perspectivas: "as transformações sociais mais amplas, que propiciaram o retorno do prestígio ao campo do político, e a própria dinâmica interna da pesquisa histórica” (FERREIRA, 1992: 267).

As vivências dos conflitos militares, os problemas que desestabilizaram o modelo econômico liberal, levando ao desenvolvimento de nova forma de atuação estatal cuja proposta consistia na elaboração de um conjunto de políticas pública que aumentaram o grau de amplitude do Estado, levando a crer que a relação entre economia e política era mais estreita do que se afirmava. Nesse sentido, constata-se:

[...] que as relações entre a economia e a política não tinham um sentido único. Se não havia dúvida de que a pressão dos interesses organizados se refletia na implementação das políticas públicas, a recíproca também era verdadeira: a decisão política podia mudar o curso da economia (FERREIRA, 1992: 267).

Paralelo a esse contexto sócio-político e econômico é notável a ocorrência de uma profunda reflexão no interior da própria historiografia que coloca em evidência a História Política, porém, de forma renovada e em contraposição àquela praticada no século XIX, trazendo em seu bojo novas perspectivas de investigação, metodologias, aparatos de pesquisa, categorias, definições teóricas; com uma abordagem mais ampla que alcançava todos os personagens da coletividade; praticante de investigações que se apropriavam dos dados quantitativos produzidos pelos levantamentos estatísticos, entre outras possibilidades.

Além disso, merece destaque o diálogo promovido entre esta História Política renovada e outros campos do conhecimento das Ciências Humanas e Sociais, segundo constata Marieta Ferreira.

Outro ponto a ser destacado nesse movimento de renovação é o contato da história com outras disciplinas, como a ciência política, a sociologia, a lingüística ou a psicanálise, que abriu novos campos e trouxe novos aportes. A pluridisciplinaridade possibilitou o uso de novos conceitos e técnicas de investigação, bem como a construção de novas problemáticas (FERREIRA, 1992: 267).

Sendo assim, o desenlace dos anos de 1970 representa o limiar de uma maneira renovada de se pensar o campo político, que passa a ser observado a partir da “[...] convicção de que a política tem uma existência própria e não é uma simples expressão

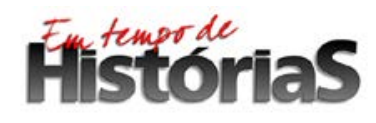

(PPGHIS/UnB) No. 33, Brasília, Ago - Dez 2018 ISSN 2316-1191 
reflexa da ação estrutural das forças econômicas” (FERREIRA, 1992: 267). Sua força está em ser, não apenas um nível autônomo perante outros níveis da sociedade, mas, como um dos fomentadores das transformações sociais.

Todo esse cenário de reelaboração da História Política está intrinsicamente relacionado ao avanço dos estudos do tempo presente e sua interação dialógica com as memórias em suas mais variadas manifestações, a esse respeito Marieta Ferreira observa que:

O aprofundamento das discussões sobre as relações entre passado e presente na história, e o rompimento com a ideia que identificava objeto histórico e passado, definido como algo totalmente morto e incapaz de ser reinterpretado em função do presente, abriram novos caminhos para o estudo da história do século XX. Por sua vez, a expansão dos debates sobre a memória e suas relações com a história veio oferecer chaves para uma nova inteligibilidade do passado (Rousso, 1993 apud FERREIRA, 2002: 320).

Em seguida, Hutton, afirma:

O interesse dos historiadores pela memória foi em grande medida inspirado pela historiografia francesa, sobretudo a história das mentalidades coletivas que emergiu na década de 1960. Nesses estudos, que focalizavam principalmente a cultura popular, a vida familiar, os hábitos locais, a religiosidade, etc., a questão da memória já estava implícita, embora não fosse abordada diretamente (HUTTON, 1993 apud FERREIRA, 2002: 320).

Pode-se conceber a possibilidade se produzir enorme discussão investigativa sobre o tempo presente, visto que a história não é estática e o historiador é fortemente influenciado pelas visões de mundo que o cercam, independentemente da localização temporal do conteúdo por ele investigado. Por ser um fenômeno ainda em andamento, o historiador pode até não ter à mão todos os artefatos disponíveis do dado momento, mas, é sua função elaborar estratégias de análise que possibilitem tirar o máximo proveito dos benefícios de seu contato concreto com a realidade estudada. É assim, então, que a memória se constitui enquanto importante ferramenta de análise do historiador em seu processo de investigação de dado conteúdo ou objeto.

Entretanto, a memória, enquanto categoria de análise possui suas possibilidades interpretativas. Maurice Halbwachs, sociólogo francês (1877-1945), estabelece o conceito de "memória coletiva", insistindo na premissa de que o episódio da 
reminiscência e circunscrição da memória não pode ser verdadeiramente investigado se não se levar em conta a realidade social na qual esse processo de reconstrução da memória está inserido. Ao mesmo tempo é necessário observar que Halbwachs segue a tradição durkheimiana que, entre outras coisas se funda “[...] em tratar fatos sociais como coisas" (POLLAK, 1989: 3). Sendo assim, estes vários elementos funcionam como referências da identidade própria de uma sociedade ou grupo social, aquilo que o define, torna especial, une e diferencia dos demais. Sempre em uma perspectiva positiva que propõe a permanência e a estabilidade.

O ponto central da análise de Halbwachs é perceber a memória como um modo de gestão do passado que, em princípio uma ocorrência particular e individual do sujeito, deve ser compreendida em sua amplitude como uma ocorrência da coletividade, socialmente constituída e submetida a oscilações e alterações contínuas.

Porém, a perspectiva de análise trazida por Halbwachs, de referência durkheimiana, vem enfrentando certa resistência por parte daqueles que optam por uma perspectiva construtivista, segundo a qual:

[...] não se trata mais de lidar com os fatos sociais como coisas, mas de analisar como os fatos sociais se tornam coisas, como e por quem eles são solidificados e dotado de duração e estabilidade. Aplicada à memória coletiva, essa abordagem irá se interessar, portanto pelos processos e atores que intervêm no trabalho de constituição e de formalização das memórias (POLLAK, 1989: 4).

Ao optar pela possibilidade analítica construtivista o historiador deve praticar algumas ações metodológicas cujos componentes principais são: a utilização da história oral como estratégia para capturar as lembranças individuais; a busca por conteúdos que revelem o caráter conflitante entre a memória oficial e as memórias subterrâneas dos segmentos sociais cujas vozes foram silenciadas e que emergiam (Cf. POLLAK, 1989: 3-15).

Halbwachs usa a categoria memória coletiva ou oficial, partindo de uma premissa afetiva, harmônica e constante. Pollak (1989: 4), por sua vez, chama atenção para “[...] o caráter destruidor, uniformizador e opressor da memória coletiva nacional”, portanto, opta por chamar de memória enquadrada em virtude do seu caráter homogeneizador que visa uniformizar e criar um espírito de corpo limitado e quebradiço. Ao mesmo tempo enfatizando que: “essas memórias subterrâneas que prosseguem seu trabalho de subversão

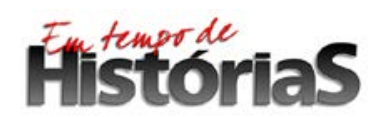


no silêncio e de maneira quase imperceptível afloram em momentos de crise em sobressaltos bruscos e exacerbados” (POLLAK, 1989: 4). Nota-se a preocupação em dar voz aos excluídos e marginalizados cujas memórias subterrâneas foram sufocadas por uma memória que se pretendia oficial e pública. Porém, as memórias subterrâneas emergem no momento em que o enquadramento da memória apresenta suas falhas e deformações, colocando-se dessa maneira a memória enquadrada e as subterrâneas em dimensão dicotômica entre si (Cf. POLLAK, 1989: 3-15).

Nesse sentido, entende-se que a utilização dos recursos metodológicos da história oral privilegia a experiência do indivíduo no processo de entendimento dos episódios sociais de ocorrência recentes, sendo assim peça fundamental para a construção de pressupostos que poderão sedimentar análises históricas que, por sua vez exerçam papel relevante na relação entre memória e história. Entretanto, a memória individual ganha razão de ser em história oral quando entrelaçada ao conjunto das memórias coletivas. Como fundamento da história oral, as memórias incidem-se na imaginação coletiva e tomam forma na representação verbal. Desta maneira a história oral, pretende assinalar a memória viva, com a pretensão de elaborar uma visão globalizante das experiências vivenciadas no decorrer da pesquisa (ALMEIDA, 2010).

Isto posto, pode-se dizer que tais relatos e testemunhos são reconhecidos como indicações significativas que podem colaborar para uma melhor fundamentação da história do tempo presente.

Assim, Lucília Delgado e Marieta Ferreira (2014: 9) afirmam que “[...] o tempo presente constitui-se como realidade temporal propícia à construção de relatos e registros de lembranças. São vozes múltiplas que muitas vezes registram formas diferentes e até conflitantes de rememoração de acontecimentos e processos”.

Entretanto, enquanto campo metodológico, a história oral ainda é alvo de inúmeras críticas por parte dos historiadores mais tradicionais o que leva seus defensores e praticantes a promoverem análises constantes no sentido de sempre aperfeiçoá-la.

Conforme assinala Marieta Ferreira:

As constantes críticas dos historiadores tradicionais à história oral estimulam aqueles que a praticam a promover uma permanente reflexão e avaliação de seus procedimentos de pesquisa. Esse esforço de resposta às críticas recebidas tem resultado num saldo positivo que não deve ser minimizado. Sem deixar de reconhecer as dificuldades da história oral, pode-se detectar no método um potencial de pesquisa extremamente

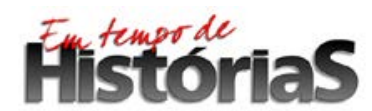

(PPGHIS/UnB) Nº. 33, Brasília, Ago - Dez 2018 ISSN 2316-1191 
rico que não deve nos impedir de tirar o proveito devido de seu uso (FERREIRA, 2002: 326).

Em virtude de seu constante processo de aperfeiçoamento, a história oral vem permitindo o apontamento de diversos relatos que se constituem fundamentais para a elaboração da memória coletiva e individual. São os mais variados indivíduos e espectadores da história que, ao serem estimulados por pesquisadores das ciências humanas e sociais, narram suas vivências que se transformam em documentos suscetíveis a reflexão crítica. À vista disso, os registros orais podem ser qualificados como fontes que carregam em si grande variedade de perspectivas de mundo e apontamentos de vivências, destacando a diversidade em oposição uniformidade que comumente reduzem e deturpam o mundo real.

Por outro lado, não é atribuição do historiador julgar a veracidade dos fatos. Sua função, ao utilizar os recursos metodológicos da história oral é problematizar a visão de mundo que norteia a narrativa oral.

Essa história [do presente], de fato, pode ser feita com testemunhas vivas e fontes proteiformes, porque é levada a desconstruir o fato histórico sob a pressão dos meios de comunicação, porque globaliza e unifica sob o fogo das representações tanto quanto das ações, pode ajudar a distinguir talvez de forma mais útil do que nunca o verdadeiro do falso. Pois se ela tem como missão; como toda história digna deste nome, mostrar a evidência científica das verdades materiais diante do esquecimento, da amnésia ou do delírio ideológico [...], ela sem dúvida está mais apta a explicar do que a verdade estatística da enumeração, da qual somos todos apreciadores; ela não evita ver em ação a verdade psicológica da intenção, a humildade verdade do plausível, a força da questão da memória sobre o curso do tempo (RIOUX, 1999: 49).

Reitera-se que a história oral enquanto possibilidade metodológica vai além da simples exação e catalogação de testemunhos. É, antes de tudo, uma possibilidade de problematização das memórias individuais e coletivas em dada realidade política, econômica e sociocultural que são trazidas à tona através dos relatos orais que e que tais memórias relatadas não são exatamente a verdade no sentido estrito, mas, uma verdade temporal e psicologicamente constituída, ou seja, as memórias descritas nos relatos são impressões readaptadas do passado. Portanto, ao realizar o trabalho de investigação dos relatos o historiador observar atentamente tanto o dito quanto o não dito, visto que, o silêncio também “fala” e que as pausas, reflexões, contemplações dizem tanto quanto as 
falas exacerbadas, entusiasmadas, contundentes. Nesse ponto é que os relatos orais são importantes ferramentas que permitem a emergência das memórias subterrâneas e, ao mesmo tempo, possibilitam seu confronto com as memórias enquadradas.

Todavia, como anteriormente destacado, as memórias expostas nos relatos orais não são a verdade no sentido estrito e por isso precisam ser confrontadas com outras fontes na intenção de promover-se a montagem de uma espécie de arsenal informativo sobre o conteúdo investigado. Isto posto, a imprensa se viabiliza como fonte de informação sobre as memórias relatadas nos depoimentos orais.

Importante fonte produzida pelos historiadores, a imprensa ${ }^{2}$ apenas bem recentemente passou a manter relação mais próxima com a historiografia. Em certa medida tal relação ocorreu em virtude da renovação da História Política que buscou, ao mesmo tempo, novas fontes de pesquisa para o historiador e novas possibilidades interpretativas do saber histórico. Essa nova maneira de ver fez com o que o historiador passasse a refletir sobre suas fontes a partir de novas perspectivas. Isto é, as fontes deixaram de ser portadoras de sentido em si, tornando-se suscetíveis a apreciação do historiador.

Compreendendo que há certo grau de semelhança, no tocante à interpretação dos fatos, entre o texto jornalístico e historiográfico, se torna viável buscar nas fontes jornalísticas a maneira como os meios de comunicação (jornais impressos, rádio, TV, mídias digitais) apresentaram e classificaram os acontecimentos relacionados às manifestações ocorridas na Polícia Militar do Maranhão no ano de 2011 e como eles foram diretamente vinculados ao tecido político local numa perspectiva de enquadrá-los ao debate nacional que girava em torno da crise da segurança pública. Sempre deixando claro que os textos jornalísticos, em suas mais variadas manifestações, se constituem em fontes riquíssimas de observação da realidade que nos cerca e que o são assim por definição arbitrária do historiador.

Porém, Cruz e Peixoto alertam que:

Os diversos materiais da Imprensa, jornais, revistas, almanaques, panfletos, não existem para que os historiadores e cientistas sociais façam pesquisa. Transformar um jornal ou revista em fonte histórica é uma operação de escolha e seleção feita pelo historiador e que supõe seu tratamento teórico e metodológico. Trata-se de entender a imprensa como linguagem constitutiva do social, que detém uma historicidade e

\footnotetext{
${ }^{2}$ Considerando aqui os jornais impressos, rádio, TV, mídias digitais.
} 
peculiaridades próprias, e requer ser trabalhada e compreendida como tal, desvendando, a cada momento, as relações imprensa/sociedade, e os movimentos de constituição e instituição do social que esta relação propõe (CRUZ e PEIXOTO, 2007: 258).

Desta forma, ao elencar as narrativas produzidas pela imprensa como fonte interpretativa do tempo presente o historiador deve levar em consideração alguns aspectos fundamentais. O primeiro deles é, mesmo compreendendo que a imprensa se constitui em fonte inestimável para seu trabalho, o historiador não pode esquecer que existem duas “temporalidades” distintas: a do momento em que o episódio foi narrado pela imprensa e a outra se refere ao momento em que o historiador analisa o episódio ocorrido. O outro aspecto fundamental é que tais narrativas não são documentos “autênticos e óbvios” e portadores da verdade em si. Faz-se necessário interagir com essas narrativas, entrecortar com outros dados e notícias, procurando compreender tanto os momentos de reticência quanto os de retirada. Sobretudo, é função do historiador preservar seu criticismo, visto que as narrativas produzidas pela imprensa são extremamente comprometidas por determinadas orientações, econômicas e ideológicas, cabendo ao historiador realizar a análise crítica e dialógica dessas narrativas, levando em consideração suas limitações e parcialidades.

\section{A Polícia Militar do Maranhão: um campo de disputas de memórias}

No dia 08 de novembro de 2011, os policiais militares, com apoio das associações de praças e liderados pelo soldado Leite e pelo cabo Campos, posicionaram dezenas de viaturas em frente à Assembleia Legislativa do Estado como ato de advertência. No dia 23 de novembro à noite, os policiais militares ocuparam a Assembleia Legislativa e lá permaneceram por 14 dias. Iniciava-se, assim, a primeira onda de manifestações realizadas por policiais militares do Maranhão em desagravo à política salarial praticada pelo governo Roseana Sarney Murad. Somam-se às questões salariais outras questões, tais como: as péssimas condições de trabalho dos policiais, infraestrutura das Companhias e Batalhões de Polícia na capital e no interior do Estado, além de inúmeros casos de abuso de poder e assédio moral praticado pelo comando da Polícia Militar e pelo próprio governo estadual contra praças e oficiais dentro ou fora de serviço.

Para bem fundamentar o exposto recorro ao depoimento do policial militar

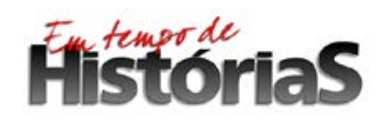

(PPGHIS/UnB) No. 33, Brasília, Ago - Dez 2018 ISSN 2316-1191 
Beltrano de $\mathrm{Tal}^{3}$ numa demonstração de como se deu o pontapé inicial das manifestações:

Houve uma reunião, mais ou menos oito horas da noite, no dia, se não me engano, de segunda-feira, decidimos que ia ter uma última reunião que seria numa quarta-feira. Ou tudo ou nada. Aí, nós fomos "pra” reunião [...]. O governo ia perder o braço dele preventivo e repressivo, às vezes [...]. Chegamos à conclusão que nós devíamos avisar o governo, primeiro, que nós vamos parar para que ele possa tomar providências para não deixar as cidades sem segurança. Então, foi comunicado ao comando geral que comunicou ao secretário de segurança que nós íamos parar. No dia seguinte, na quarta-feira, às oito horas da noite, já estava tudo alinhavado, acertado. Nós paramos a polícia militar e ocupamos a assembleia legislativa (entrevista realizada em 14/12/18).

Essas manifestações representaram a primeira grande quebra dos princípios da hierarquia e disciplina que fundamentam a lógica da Polícia Militar do Maranhão e de todas as instituições Militares Brasileiras, representando uma rachadura, visto "até hoje, na polícia militar tem 182 anos, e nunca teve um movimento assim” (BELTRANO DE TAL, 14/12/2018). Todavia, essas manifestações podem ser mais bem compreendidas se forem analisadas em seu contexto. Nesse sentido, é necessário confrontar as noções básicas que fundamentam o militarismo, suas práticas cotidianas por vezes abusivas com um conjunto de insatisfações que tomavam conta dos quadros da Policia Militar do Maranhão.

Numa visão geral, é preciso pontuar que as Polícias Militares atrelaram-se institucionalmente ao Exército durante o Regime Militar por força do Decreto-lei nº 667, de 1969, fazendo-as ter basicamente a mesma formação no que diz respeito à estrutura das normas de conduta baseadas nos princípios da disciplina e hierarquia, uma vez que o Regime Disciplinar das Polícias Militares (RDPM) é fundamentado no Regulamento Disciplinar do Exército (RDE). Apesar da democratização do país, a Constituição de 1988 preservou o atrelamento entre essas instituições, tornando as Polícias Militares forças auxiliares do Exército, conforme artigo 144, § 6º da Constituição Federal (BRASIL, 1988), e proibindo tanto sua organização sindical quanto seu envolvimento e movimentos grevistas ou qualquer manifestação similar previsto no artigo 142, § $3^{\circ}$, IV (BRASIL,

\footnotetext{
${ }^{3}$ Em virtude de temerem represálias por parte do alto comando da Polícia Militar do Maranhão os entrevistados não terão seus nomes ou patentes revelados, dessa forma, optou-se pela escolha de nomes fictícios. Os depoimentos citados não seguem a norma culta estão conforme a fala informal de seus personagens. Todas as entrevistas citadas no texto foram coletas pelo autor e fazem parte de seu acervo de pesquisa.
} 
1988). Portanto, militar, seja das Forças Armadas, seja das Polícias Militares e dos Corpos de Bombeiros estaduais, das forças auxiliares e das reservas do Exército estarão incorrendo em crime de insubordinação (BICUDO, 2000).

O atrelamento da Polícia Militar ao Exército não se esgota na dimensão jurídicoinstitucional. Ao contrário. A Polícia Militar, via de regra, recebe treinamento e desfruta de uma forte cultura militar oriunda do Exército, cujos preceitos são calcados em princípios que conduzem os membros dos seus quadros a crerem em sua superioridade em comparação aos demais cidadãos. Na academia de polícia se aprende e apreende o espírito de corpo ou espírito militar cuja construção se dá a partir da valorização da coletividade em detrimento da individualidade numa nítida intenção de dar ao militarismo um sentido de ordem e sincronicidade (CASTRO, 1990).

Como se destacou anteriormente, a redemocratização do Brasil não alterou a estrutura hierárquica e disciplinar das policias militares e manteve o caráter militar atrelado ao Exército. Todavia, isso não evitou que as demandas democráticas que tomavam conta do país não as alcançassem. Exemplo disso foi a criação das associações de policiais militares. Tais associações atuavam já em 2011, tanto como entidades de cunho recreativo quanto de representação dos interesses e assistência jurídica dos policiais, mas que, por muito tempo, timidamente, apenas mediavam as negociações entre os policiais militares, Comando da Polícia Militar e Governo na esfera administrativa. Não tardou até essas relações de forças extrapolarem os limites do diálogo e da negociação e desembocarem em uma onda de manifestações no seio da Polícia Militar do Maranhão.

O depoimento do policial militar Beltrano de Tal relata um pouco da referida situação:

Todos os presidentes de associação vieram para São Luís. Foram traçadas diretrizes, estratégias, planejamentos e discutimos que só tinham uma maneira de alcançar o objetivo: para todo mundo!

Antes disso houve muito acordo [...]. O secretário de segurança prometeu muita coisa e já estava fazendo um ano. Péssimas condições de trabalho, salário ruim. Então, tudo isso dificultava a prestação de serviço da polícia militar e nos deixando angustiados (entrevista realizada em 14/12/2018).

Passados praticamente sete anos, as memórias do movimento tornam-se importantes objetos de análise para investigação e compreensão dos pressupostos que

\section{Filistororias}


fazem da Polícia Militar do Maranhão uma instituição que, apesar de se apresentar acima da sociedade civil $^{4}$, se configura como espaço de disputas que refletem o tecido político estadual e nacional com suas alianças, apadrinhamentos, perseguições e posturas autoritárias que por vezes ultrapassam os limites da razoabilidade. Inclusive, muitos se negaram a colaborar com esta pesquisa alegando que, por terem participado das manifestações, são perseguições até hoje pela instituição.

Por isso, torna-se importante a reflexão sobre o que dizem ou não, do que lembram e sentem os policiais envolvidos direta ou indiretamente ${ }^{5}$, no que se refere às manifestações de 2011 no calor dos acontecimentos. Não apenas destacando o encontro, mas, também, o desencontro entre essas memórias. Mas, deixando claro que as memórias enquanto campo de gestão do passado são sempre narradas em função do presente e das vivências do sujeito em dado contexto social. Tudo isso com o propósito de verificar a existência de rachaduras memoriais que permitam perceber as disputas entre as memórias das manifestações, algo que podemos corroborar no que escreve Neves quando diz que "memória e transmissão de experiências são faces diferentes de um único cristal que inclui a História. A memória é retenção do passado atualizado pelo tempo presente. Articula-se com a vida através da linguagem, que tem na narrativa uma de suas mais ricas expressões” (NEVES, 2006: 59).

O desencontro entre as memórias pode ser percebido quando se avalia os resultados das manifestações no que diz respeito especialmente ao acordo firmado entre a comissão que representava os policiais e o governo. De um lado temos a fala do policial militar Beltrano de Tal:

Veio aí uma parte que nós também já estávamos prevendo que se chama desgaste físico. Toda greve tem um ápice e depois ela começa a cair. Nós tínhamos que acabar com esse movimento em dez dias porque a tropa não vai aguentar. Vai haver o desgaste. A família vai cobrar. Havia as ameaças. Vai ter conflito com as forças armadas. E assim foi feito.

Mas, na realidade nós já tínhamos combinado que a greve devia acabar em dez dias. O tempo foi passando e nós começamos a perceber que alguns companheiros já estavam cabisbaixos e desmotivados. Com dez dias nós fomos chamados ao palácio e lá fizemos os acordos com o representante do governo, o senador João Alberto (entrevista realizada em 14/12/2018).

\footnotetext{
${ }^{4}$ Em virtude dos princípios norteadores e dos códigos de honra e conduta que a fundamentam.

${ }^{5}$ Oficiais, comando da Polícia Militar, imprensa e Governo do Estado.
}

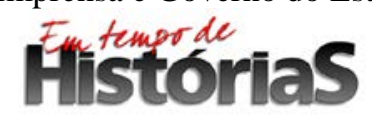


Por sua vez, o policial militar Fulano de Tal afirma:

Eu, particularmente, me senti enganado pela comissão principalmente porque a gente pedia $17 \%$ de reajuste salarial e a comissão aceitou $10,41 \%$. "Pra" piorar ainda mais as coisas, o governo assumiu que atenderia todas as pautas, mas, atendeu apenas e parcialmente a parte salarial. O restante não se tornou realidade. Pela experiência que eu tenho hoje teria pedido 30\% "pra” receber esses 17\% (entrevista realizada em 11/11/2018).

Embora nas narrativas sobre as manifestações seja possível notar que há concordância por parte dos policiais envolvidos direta ou indiretamente, oficiais, comando da Polícia Militar, imprensa e Governo do Estado em relação aos acontecimentos, a disputa memorial se apresenta na forma como esses acontecimentos foram absorvidos tanto na dimensão individual quanto na coletiva, ou seja, as manifestações de 2011 foram interpretadas de diversas maneiras. Entretanto, nota-se que essas diversas percepções podem ser organizadas de forma que possibilite investigar as disputas entre as memórias enquadradas da Polícia Militar do Maranhão enquanto instituição coesa e dotada de inúmeras características que lhe dão identidade profundamente marcada pela disciplina e respeito pela hierarquia e obediência às autoridades militares e civis, mas, também, as memórias subterrâneas daqueles que por terem participado das manifestações, foram alvo de perseguições e objetos de sanções e punições no âmbito da informalidade, visto que, oficialmente todos os envolvidos foram anistiados.

Podemos verificar tal posição acima menciona em um dos depoimentos cedido pelo policial militar Cicrano de Tal, em que afirma:

Ainda hoje sofro perseguição por causa lá daquela história. Não me
arrependo porque a gente não pode se arrepender do que fez, mas, do
que não fez. Só que eu era de São Luís e me mandaram “pro” interior.
O pessoal da minha barra tudo já são segundo tenente e eu não saio de
sargento. Pelo menos não fui expulso (entrevista realizada em
15/12/2018).

Por um lado, a imprensa ${ }^{6}$ e parte dos policiais diretamente envolvidos nas

\footnotetext{
${ }^{6}$ Independentemente de seu posicionamento político no momento das manifestações a imprensa optou pela terminologia greve tanto para enaltecer quanto para condenar, sabendo-se que aos policiais militares era vetado esse direito.
} 
manifestações percebem estas enquanto greve ou, até mesmo, como ato político em que os policiais militares buscavam o direito de ter direitos, demonstrando certo orgulho de terem participado do evento e com clara intenção de confronto e enfrentamento. Sentimento compartilhado por muitos que embora não tenham participado diretamente tomam para si a memória dos acontecimentos.

Sobre a possibilidade de enfrentamento com as forças federais convocadas pelo Governo do Estado o policial militar Beltrano de Tal relatou em tom de orgulho:

[...] O resultado de tudo isso foi que veio um general, comandante da décima região militar, general Gomes de Mattos, que disse que ia trazer tropas de paraquedistas da Polícia do Exército de Pernambuco para tomar de assalto a assembleia. Eu disse, para um coronel assessor do general Gomes de Mattos que preferia entrar na minha casa com minha tropa morta que entrar como covarde (entrevista concedida em $14 / 12 / 2018)$.

A esse respeito Pollak denomina de entrelaçamento entre memórias individuais e coletivas fazendo a seguinte reflexão:

Quais são, portanto, os elementos constitutivos da memória, individual ou coletiva? Em primeiro lugar, são os acontecimentos vividos pessoalmente. Em segundo lugar, são os acontecimentos que eu chamaria de 'vividos por tabela', ou seja, acontecimentos vividos pelo grupo ou pela coletividade à qual a pessoa se sente pertencer. São acontecimentos dos quais a pessoa nem sempre participou, mas que, no imaginário, tomaram tamanho relevo que, no fim das contas, é quase impossível que ela consiga saber se participou ou não. Se formos mais longe, a esses acontecimentos vividos por tabela vêm se juntar todos os eventos que não se situam dentro do espaço-tempo de uma pessoa ou de um grupo. É perfeitamente possível que, por meio da socialização política, ou da socialização histórica, ocorra um fenômeno de projeção ou de identificação com determinado passado, tão forte que podemos falar numa memória quase que herdada (POLLAK, 1992: 201).

Entretanto, muitos, aderindo ao enquadramento da memória, embora reconheçam a importância das manifestações, evitam categorizá-las como greve em razão de considerar a expressão ofensiva à identidade militar ou por ser uma prática mais comum aos movimentos de esquerda ${ }^{7}$. Fulano de Tal declara que "não vejo como greve, esta

\footnotetext{
${ }^{7}$ Uma onda conservadora que tomou conta do país a partir de 2013 levou à exacerbação do ataque e da perseguição aos movimentos de esquerda e na Polícia Militar do Maranhão houve claramente a adesão de parte de seus quadros a aderirem a esse conservadorismo.
} 
denominação foi cunhada pela imprensa. Nós sempre consideramos como movimento paredista e não greve, justamente por não enquadrar juridicamente no conceito de greve” (FULANO DE TAL, 11/11/2018). Por outro lado, muitos oficiais, o comando da Polícia Militar e o próprio Governo Estadual são enfáticos em enquadrar as manifestações de 2011, enquanto ato de insubordinação, em virtude dos policiais militares não possuírem o Direito de greve (art. 142, § 30, IV, CF) ou, até mesmo, uma pecha na trajetória da Polícia Militar do Maranhão.

Imediatamente a Polícia Militar do Maranhão entrou com uma representação solicitando ao Ministério Público que requeresse à Justiça Militar a prisão dos líderes das manifestações, como consta na seguinte matéria publicada no dia 24/11/2011, intitulada “Polícia pede ao MP prisão dos líderes da greve”:

O responsável pelo inquérito que investiga o movimento grevista da Policia Militar do Maranhão, coronel Edilson Moraes Gomes, entrou nesta quinta-feira, 24, com uma representação na Procuradoria Geral de Justiça solicitando que o Ministério Público do Maranhão requeira, junto a Justiça Militar, a prisão preventiva dos lideres do movimento.

A solicitação foi apresentada à promotora de Justiça Militar do Maranhão, Maria do Socorro Assunção Gomes, que encaminhará a representação ao Auditor Militar do Estado solicitando a prisão dos referidos grevistas.

De acordo com a promotora, pela própria Constituição Brasileira, Artigo 142, e conforme estabelece o Artigo 24 da Constituição Estadual, a greve dos militares é ilegal, ou seja, fere a lei e o Ministério Público como fiscal da lei não pode compactuar com a situação.

Segundo Maria do Socorro os lideres do movimento afrontam a garantia da ordem pública e a exigência da manutenção das normas ou princípios da hierarquia e disciplinas militares, conforme o Artigo 255 do Código de Processo Penal Militar (SOARES, 2011).

O Governo do Estado também tomou providências no sentido de inviabilizar as manifestações como se vê em nota publicada no dia 24/11/2011, intitulada “Justiça decreta greve da polícia ilegal”:

O Tribunal de Justiça do Maranhão (TJ-MA) considerou ilegal a greve da Polícia Militar e Corpo de Bombeiros iniciada ontem à noite. A ação foi protocolada hoje cedo pelo governo do Estado. De acordo com a decisão do desembargador Stélio Muniz foi estipulada ainda multa no valor de R\$ 200 por dia de trabalho que cada policial ou bombeiro continuar de braço cruzado. Os grevistas permanecem ocupando a sede da Assembleia Legislativa. Eles acompanharam na galeria a sessão ordinária realizada na manhã desta quinta-feira (SOARES, 2011).

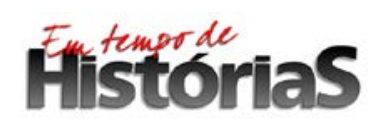

(PPGHIS/UnB) No. 33, Brasília, Ago - Dez 2018 ISSN 2316-1191 
Sobre o pedido de prisão dos líderes das manifestações a matéria publicada em 25/11/2011, intitulada “Auditor julga improcedente prisão de líderes da greve”, afirma:

O juiz auditor militar em São Luís, Vicente de Paula Gomes de Castro, julgou improcedente o pedido da Corregedoria da Polícia Militar (PM) para decretar a prisão de quatro líderes da greve da PM e dos bombeiros do Maranhão.

O pedido, feito ontem (24) pelo encarregado do inquérito que investiga o movimento grevista da PM do Maranhão, coronel Edilson Moraes Gomes, alega crime de desobediência, porque os militares são proibidos pela Constituição de fazer greve. (SOARES, 2011)

Todavia, apesar das perseguições durante e após as manifestações, os policiais militares envolvidos insistem em exaltar suas memórias. O policial militar Beltrano de Tal destaca que na tentativa de encorajar os companheiros e despertar seu espírito de corpo disse: "Nós só temos uma opção: fazer o movimento sabendo que nós vamos enfrentar as baionetas. Não tem outro jeito. Vamos sangrar. Quem tá disposto?” (BELTRANO DE TAL, 24/12/2018).

A inclusão das manifestações de 2011 como ato de insubordinação incompatível com o militarismo, como pregam parte dos oficiais, Comando, parte da imprensa e o Governo Estadual de então, visa claramente tratar o episódio como ato isolado que fere, mas, não destrói, conforme a própria polícia, os pilares que sustentam a instituição policial militar do Maranhão, preservando o enquadramento de uma memória que se acreditava consolidada. Por outro lado, a memória enquadrada se confronta com as memórias subterrâneas dos policiais que compreendem as manifestações como marco na luta dos policiais pelo direito de ter direitos.

\section{À guisa de uma conclusão}

A Nova História Política vem demonstrando, desde sua renovação no final da década de 1970, ser importante campo teórico de análise do tempo presente. E que auxiliada por outras disciplinas pode promover a construção de novas abordagens, conteúdos e metodologias de pesquisa historiográfica.

Muitos historiadores brasileiros têm dado mais atenção à Nova História Política como possibilidade interpretativa das disputas entre as memórias enquadradas e as memórias subterrâneas. Embora os estudos da História da Polícia seja algo bastante 
recente no Brasil, eles vêm se configurando como perspectivas possíveis para compreensão do tecido político, tanto numa dimensão estadual quanto nacional.

Portanto, compreende-se que a Polícia Militar do Maranhão, enquanto instituição é conteúdo de estudo da Nova História Política dos mais significativos por permitir a compreensão da cultura política maranhense com seus clientelismos, sua rede de bajulação, perseguição e apadrinhamento tipicamente oligárquicos.

\section{Referências Bibliográficas}

ALMEIDA, Juniele Rabêlo de. Tropas em protesto: o ciclo de movimentos reivindicatórios dos policiais militares brasileiros no ano de 1997. São Paulo, 2010. Tese (História Social) - Universidade de São Paulo, 2010.

BELTRANO DE TAL. Entrevista concedida a Paulo Henrique Matos de Jesus. São Luís, 14 de dezembro de 2018, gravada por meio digital.

BICUDO, Hélio. A unificação das polícias no Brasil. Estudos Avançados, São Paulo: Instituto de Estudos Avançados da USP, n. 40, p. 91-106, 2000.

BRASIL. Constituição (1988). Constituição da República Federativa do Brasil. Disponível em: <http://www.senado.gov.br/atividade/const/con1988/CON1988_05.10.1988/art_144_.asp.> Acesso em: 20 jul 2018.

Constituição (1988). Constituição da República Federativa do Brasil. Disponível em <http://www.senado.leg.br/atividade/const/con1988/con1988_12.07.2016/art_142_.asp.> Acesso em: 20 jul 2018.

CASTRO, Celso. O Espírito Militar: um estudo de Antropologia Social na Academia Militar das Agulhas Negras. Rio de Janeiro: Jorge Zahar Editor, 1990.

CICRANO DE TAL. Entrevista concedida a Paulo Henrique Matos de Jesus. São Luís 11 de novembro de 2018, gravada por meio digital.

CRUZ, Heloísa de Freitas; PEIXOTO, Maria do Rosário da Cunha. Na oficina do Historiador: conversas sobre história e imprensa. Projeto História: Revista do Programa de Estudos Pós-Graduados de História, São Paulo, v. 1, n. 35, p. 253-270, dez. 2007.

DECRETO-LEI No 667 de 1969. Disponível em <http://www.planalto.gov.br/ccivil_03/DecretoLei/Del0667.htm>, acesso em 20 jul. 2018.

DELGADO, Lucilia de Almeida Neves; FERREIRA, Marieta de Jesus (Org.). História do tempo presente. Rio de Janeiro: FGV Editora, v. 1, 2014.

FERREIRA, Marieta de Moraes. A Nova "Velha História": O Retorno da História Política. Revista Estudos Históricos, v. 5, n. 10, p. 265-271, 1992.

FULANO DE TAL. Entrevista concedida a Paulo Henrique Matos de Jesus. São Luís, 11 de novembro de 2018, gravada por meio digital.

HARTOG, François. Regimes de historicidade: presentismo e experiências do tempo. Tradução de Andréa S. de Menezes, Bruna Beffart, Camila R. Moraes, Maria Cristina de A. Silva e Maria Helena Martins. Belo Horizonte: Autêntica, 2014.

, François. Tempo, história e a escrita da história: a ordem do tempo. Revista de História, n. 148, p. 09-34, 2003. Disponível em <http://www.revistas.usp.br/revhistoria/article/>, acesso em 27 jul. 2018.

KOSELLECK, Reinhart. Futuro Passado: contribuição à semântica dos tempos históricos. Rio de Janeiro: Contraponto, 2006.

Reinhart. Los estratos del tiempo: studios sobre la historia. Barcelona: Paidós Ibérica, 2001.

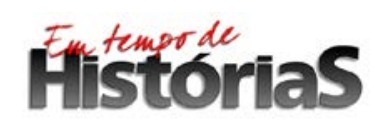

(PPGHIS/UnB) No. 33, Brasília, Ago - Dez 2018 ISSN 2316-1191 
NEVES, Lucilia de Almeida. História Oral: memória, tempo, identidades. Belo Horizonte: Autêntica Editora, 2006.

POLLAK, Michael. Memória e identidade. Revista Estudos Históricos, Rio de Janeiro, v. 5, n. 10, p. 200212, 1992.

Michael. Memória, esquecimento, silêncio. Revista Estudos Históricos, Rio de Janeiro. v. 2, n. 3, p. 3-15, 1989.

RIOUX, Jean Pierre. Pode-se fazer uma história do presente? In: CHAUVEAU, Agnè; TÉTARD, Philippe. Questões para a História do Presente. São Paulo: EDUSC, 1999, p. 39-50.

SOARES, Zeca. Polícia Militar pede ao MP prisão de líderes da greve. São Luís, 24 de nov. 2011. Disponível em <https://www.blogsoestado.com/zecasoares/2011/11/24/policia-militar-pede-ao-mpprisao-de-lideres-da-greve/>. Acesso em 06 de agosto de 2018.

. TJ considera greve dos policiais e bombeiros ilegal. São Luís, 24 de nov. 2011. Disponível em $<$ https://www.blogsoestado.com/zecasoares/2011/11/24/tj-considera-greve-dos-policiais-e-bombeiros-

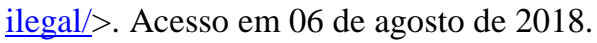

Auditor militar julga improcedente prisão de líderes da greve. São Luís, 25 de nov. 2011. Disponível em <https://www.blogsoestado.com/zecasoares/2011/11/25/auditor-militar-julgaimprocedente-prisao-de-lideres-da-greve/>. Acesso em 09 de agosto de 2018. 